\title{
Pain-Related Knowledge and Barriers among Jordanian Nurses: A National Study
}

\author{
Waddah Mohammad D'emeh1, Mohammed Ibrahim Yacoub', Muhammad Waleed \\ Darawad', Talal Haider Al-Badawi², Batool Shahwan' ${ }^{1}$ \\ ${ }^{1}$ School of Nursing, The University of Jordan, Amman, Jordan \\ ${ }^{2}$ Nursing Sciences Department, Al-Farabi Colleges, Riyadh, Saudi Arabia \\ Email:w.demeh@ju.edu.jo,m.yacoub@ju.edu.jo,m.darawad@ju.edu.jo,talal5656@yahoo.com, \\ batoolsh@hotmail.com
}

Received 13 March 2016; accepted 16 April 2016; published 19 April 2016

Copyright (C) 2016 by authors and Scientific Research Publishing Inc.

This work is licensed under the Creative Commons Attribution International License (CC BY). http://creativecommons.org/licenses/by/4.0/

CC) (i) Open Access

\begin{abstract}
The purpose of this study is to explore Jordanian nurses' knowledge and attitudes regarding pain assessment, and barriers to intervention at different hospitals representing health care sectors in Jordan. A descriptive cross-sectional design was used in this study utilizing self-administered questionnaires to collect data from nurses working in public, University-affiliated, and private hospitals located on the north, mid, and south of Jordan using Nurses' Knowledge and Attitudes Survey Regarding Pain, $(n=439)$. The mean of total correct answers on the 32 knowledge questions was $13.39(S D=4.31)$. Nurse-related barriers to effective pain management include patient history of alcohol abuse or drug addiction, and nursing staff reluctant to contact physician for analgesic order. Nurses working in surgical units, employed at private hospitals, holding a master degree, or who attended educational course or program scored significantly higher than other nurses. The results demonstrated knowledge deficit and attitude and that nurses underestimated and undertreated patients' pain. Serious efforts should be taken in nursing schools and hospitals to prepare nurses and equip them with comprehensive knowledge tools to assess and manage pain appropriately.
\end{abstract}

\section{Keywords}

Barriers, Hospitalized Patients, Jordan, Nurses' Knowledge, Pain Management

\section{Introduction}

Pain is a complex phenomenon that is a lived experience by most of the hospitalized patients [1] [2], causing 
more suffering, slower recovery [3], higher rate of complications, anxiety, sleep disturbance and lower quality of life [4]. Ineffective pain management can affect patients' physiologic, psychological, and financial status [5] [6] [7]. In 2011, the Institute of Medicine (IOM) declared that pain was in undertreated condition in the United States [8]. Therefore, healthcare providers started to have interest in pain management, and the Joint Commission on Accreditation of Healthcare Organizations (JCAHO) included pain in the definition of vital signs [9].

Despite the vast increment in the body of knowledge, richness of research, and technological advancement, hospitalized patients are still having unnecessary pain suffering [10]-[12], and that pain is still undertreated, for instance, the European Association of Palliative Care reported that $43 \%$ of Swedish cancer patients suffered from pain, and $18 \%$ of them did not receive any pain medication even though they graded their pain as moderate [13]. Not only that pain is a common symptom that is considered as a pre-existing complaint in the intensive care units [14] and a common problem in the emergency departments [15], many reasons were suggested for this phenomenon of pain under-treatment including healthcare providers' suboptimal education, inadequate pain assessment, lack of knowledge regarding pain medications and other pain management approaches [16].

Among healthcare providers, nurses are 24-hour responders to pain and pain management, and they have a crucial role in pain management through effective pain assessment, proper implementation and evaluation of pain management interventions [17]. To be effective, nurses need sufficient knowledge and positive attitudes [18], and attribute as much priority to pain management [19]. However, nurses are confronted with barriers to effective pain management, which are challenging and often not clearly identified [20] [21].

Nurse-related barriers include heavy workload, lack of time, patients' inability to cooperate [22], nurses' limited authority, limited nurse-patient relationship, and disturbance of pain management interventions [23], inadequate time for health teaching with patient, inadequate time to deliver non-pharmacological pain relief measures, staff reluctant to administer opiates and fear of pain addiction side effect on patients [20]. However, the lack of knowledge regarding pain management was the most important. For instance, nurses' average knowledge score was 47.7\% in Hong Kong using the Nurses Knowledge and Attitudes Survey (NKAS) [18], 53.4\% in Taiwan [24], 73.8\% in North Ireland [25], 76\% in USA [26], 77.2\% in Turkey [27], 55\% in Italy [28] and $48.3 \%$ in Jordan [29]. Knowing that the passing score for the NKAS is $80 \%$ [17], the above-mentioned figures indicate a severe deficit in nurses' pain management knowledge.

Jordanian patients reported relatively higher levels of pain compared to other countries [30]. Also, Jordanian patients in the intensive care units ranked pain as the second most stressful stressor; having tube in nose or mouth was the first [31]. Nurses in Jordan were found to have a lower level of pain management knowledge than that reported worldwide [29]. In Jordan, the role of nurses in pain management is to fulfill physicians' orders with no obvious guidelines [32].

Limited information is available and few studies assessed Jordanian nurses' knowledge and attitudes regarding pain management. Those studies had certain limitations including using qualitative research approach [32], including small sample sizes [29], including nurses from one hospital or from one or two nursing specialty [30]. Such limitations hinder the generalizability of the results, and call for additional studies to assist in filling the gap in this important field of patient care. Therefore, the overall aim of this study is to explore Jordanian nurses' knowledge and attitudes regarding pain assessment and intervention at different hospitals representing health care sectors in Jordan. Specifically this study attempted to answer the following research questions:

1) What are the current nurses' knowledge and attitudes of pain assessment and intervention?

2) What are the identified influencing barriers to effective pain assessment and intervention?

3) What is the relationship between nurses' knowledge and attitudes regarding pain management and their demographic characteristics?

\section{Method}

\subsection{Design}

A descriptive cross sectional design was used in this study utilizing a questionnaire for data collection about nursing knowledge and attitude regarding pain assessment and intervention.

\subsection{Sample and Setting}

The target population of this study was Jordanian registered nurses working in one of the following clinical 
areas/units: medical, surgical, intensive care units (ICU), orthopedic, pediatrics, oncology, and emergency room (ER). There were no limitations for age, year of experience or type of employment (full or part time). Participants were selected using a non-probability, convenience-sampling plan. Data was collected from nine hospitals located at the north, mid, and south of Jordan to provide national representation. Selected hospitals were large hospitals representing the major three health care sectors in Jordan (public, University-affiliated and private). A total of 745 questionnaires were distributed and 439 returned with response rate $59 \%$. The calculated sample size was done using $\mathrm{G}$ power software, in which the estimated sample was at least 432 nurses.

\subsection{Instruments}

The Nurses knowledge and Attitudes Survey Regarding Pain (NKAS) tool originally developed by McCaffery \& Ferrell in 1987 was modified with permission by Al-Shaer, Hill, \& Anderson [33]. Data regarding level of pain knowledge and attitudes were collected using a modified version of the NKAS [33]. The NKAS is a closed-answer questionnaire which composed of 21 true or false statements, 7 multiple choice items, 2 case studies with 2 multiple choice item each, and 10 questions address possible barriers to effective pain management in nurses' care area for a total of 42 questions. The modified tool excluded 6 caner pain questions. The reason why these items excluded is to eliminate any advantage oncology nurses have over the rest of the sample. A previous research finding shows a higher knowledge scores in favor of nurses who are working on oncology wards. The NKAS has well established psychometric properties. Test-retest reliability was also established ( $\mathrm{r}>$ 0.80 ) and internal consistency reliability was established (alpha $r>0.70$ ). It has been recommended to avoid distinguish items a measuring either knowledge or attitudes due to the overlap in some item, and to report the percentage of correct responses [34]. Correctly answered scores given "one" and incorrect or unanswered item given "zero"; total score ranged from (0 - 32). Participant's score calculated by dividing the total number of correctly answered items by the total number of items (X/32). Demographic data were collected using a researcher's designed questionnaire developed for the purpose of this study. It included sections covering demographic information, educational background, and clinical unit. The data were also include age, gender, employment setting, and term of employment. Also, Nurses were asked to mention if any educational programs or courses previously received in relation to pain management.

\subsection{Procedure}

Closed-answer questionnaires were distributed by hand to the different assigned clinical areas and the participants were asked to complete and return the questionnaire in sealed envelopes to the head nurse office in each assigned area. All participants were given information about voluntary nature of the study participation. A member of the research assistant team provide an oral and written presentation concerning conditions of participation in the study to groups of interested nurses from each of the selected units. At the end of the oral presentation, the research assistant invited nurses to participate in the study, answer any questions, distribute questionnaire to interested persons, notified participants that they can select free time to complete the questionnaires and to use a private room available for completion of the questionnaires. Time to recollect the questionnaires were arranged individually from each clinical unit.

\subsection{Ethical Consideration}

The approval from the Institutional Review Boards (IRB) at our academic institution and the selected hospital were obtained. Each participant was provided information about this study explaining the purpose and voluntary nature of participation and that they could withdraw at any time. Participants' were assigned a code number by the researcher, in lieu of their name and hospital, on the questionnaires. There were no identifiable names collected from the nurses and all data kept confidential in private closed cabinet at the principal investigator' office.

\section{Results}

\subsection{Characteristics of the Nurses}

Data was collected from 9 hospitals located on the north, mid, and south of Jordan. A total of 439 nurses participated in this study and completed the questionnaires (59\%), which were analyzed. Nurses from the private 
sector returned the greatest percentage of the surveys $(73 \%)$, compared to nurses from university-affiliated and public sectors, who had a response rate of $(61 \%)$ and $(36 \%)$ respectively.

The majority of the nurses who responded were aged between $18-25$ years (33.7\%), between 26 and 35 years (27.6\%). More female nurses $(54.2 \%)$ than male nurses $(44.8 \%)$ were completed the surveys. The participants were predominantly have $(1-5)$ years of experience $(n=213,48.5 \%)$, and the majority indicated that baccalaureate degree in nursing as highest education $(n=365,81.1 \%)$. The sample demographic characteristics are presented in Table 1.

\subsection{Nurses Knowledge of Pain Management}

Regarding nurses' knowledge of pain management issues, the mean of total correct answers on the 32 knowledge questions was $13.39(41.84 \%)(S D=4.31)$. The lowest score was 8 , and none of the participants correctly answered all questions; range of correct answers was $25.0 \%$ to $65.6 \%$. Table 2 shows the percentage of correct responses for the true/false questions of the knowledge section of the survey. As can be seen in this table, participants were more likely to answer correctly questions concerning the influences of individual characteristics on pain perception, side effect of opioids, nurse role in pain management, and patient self report of pain (items 6 , $13,18,19 \& 20$ respectively).

Table 3 contains a breakdown of the percentage of responses of the multiple-choice questions. As can be seen, almost half of nurses chose correctly the intravenous route as the route of choice for the administration of opioid

Table 1. Characteristics of nurses who completed the survey $(n=439)$.

\begin{tabular}{|c|c|c|}
\hline Variable & Frequency (n) & Percentage $(\%)$ \\
\hline \multicolumn{3}{|l|}{ Type of Education } \\
\hline Associate & 56 & 12.7 \\
\hline Baccalaureate & 356 & 81.1 \\
\hline Diploma & 27 & 6.2 \\
\hline \multicolumn{3}{|l|}{ Age } \\
\hline $18-25$ & 148 & 33.7 \\
\hline $26-35$ & 121 & 27.6 \\
\hline $36-45$ & 80 & 18.2 \\
\hline $46-55$ & 60 & 13.7 \\
\hline $56-65$ & 30 & 6.8 \\
\hline \multicolumn{3}{|l|}{ Years of Experience } \\
\hline $16+$ or more years & 38 & 8.7 \\
\hline $11-15$ & 36 & 8.2 \\
\hline $6-10$ & 96 & 21.9 \\
\hline $1-5$ & 213 & 48.5 \\
\hline Less than 1 year & 56 & 12.8 \\
\hline \multicolumn{3}{|l|}{ Clinical Area/Unit } \\
\hline Medical & 97 & 22.1 \\
\hline Surgical & 75 & 17.1 \\
\hline Orthopedics & 63 & 14.4 \\
\hline Oncology & 25 & 5.7 \\
\hline ICU & 85 & 19.4 \\
\hline Pediatrics & 48 & 10.9 \\
\hline ER & $\begin{array}{l}40 \\
46\end{array}$ & 10.5 \\
\hline \multicolumn{3}{|l|}{ Gender } \\
\hline Male & 201 & 45.8 \\
\hline Female & 238 & 54.2 \\
\hline \multicolumn{3}{|c|}{ Attended educational programs or courses } \\
\hline Yes & 154 & 35.1 \\
\hline No & 285 & 64.9 \\
\hline \multicolumn{3}{|l|}{ Employment setting } \\
\hline Private hospitals & 119 & 27.1 \\
\hline University-affiliated hospitals & 96 & 21.9 \\
\hline Public hospitals & 224 & 51.0 \\
\hline
\end{tabular}


Table 2. Responses to true-false statement of the survey.

\begin{tabular}{|c|c|c|}
\hline Question & $\begin{array}{l}\text { Percent correct } \\
\text { scores }(\%)\end{array}$ & $\begin{array}{l}\text { Percent incorrect } \\
\text { scores }(\%)\end{array}$ \\
\hline 1. Observable changes in vital signs needed to verify pain & 28.7 & 71.3 \\
\hline 2. Distraction equates with low pain intensity & 43.1 & 56.9 \\
\hline 3. Patient may sleep in spite of severe pain & 37.4 & 62.6 \\
\hline 4. Comparable stimuli in different people produce the same intensity of pain & 46.7 & 53.3 \\
\hline 5. Non-drug interventions rarely helpful for severe pain & 42.4 & 57.6 \\
\hline 6. Respiratory depression not common in opioid users & 61.5 & 38.5 \\
\hline 7. Aspirin $650 \mathrm{mg}$ PO analgesic effect equal to Demerol $50 \mathrm{mg}$ PO & 50.3 & 49.7 \\
\hline 8. WHO ladder suggests single analgesic agents & 30.3 & 69.7 \\
\hline 9. Phenergan is a reliable potentiator of opioid analgesic & 51.7 & 48.3 \\
\hline 10. Substances abusers should not be given opioids for pain & 31.9 & 68.1 \\
\hline 11. Elderly patients require less opioid for pain & 46.2 & 53.8 \\
\hline 12. Patient should endure pain before using medication & 34.6 & 65.4 \\
\hline 13. Religious/cultural beliefs influence pain perception & 65.6 & 34.4 \\
\hline 14. Patient's response helps in deciding the adjusted doses & 48.3 & 51.7 \\
\hline 15. Patient should use non-drug therapies alone & 25.0 & 75.0 \\
\hline 16. Placebo useful for determining existence of pain & 44.6 & 55.4 \\
\hline 17. Heat and cold should be applied only to painful area & 59.2 & 40.8 \\
\hline 18. Patient's self-report of pain is the most reliable indicator of pain & 61.3 & 38.7 \\
\hline 19. Sedation, nausea, constipation are common side effects of opioid analgesics & 60.6 & 39.4 \\
\hline 20. Physician's orders limits nurse pain management role & 63.1 & 36.9 \\
\hline 21. Pain assessment by physician or nurse is more accurate than patient's self-report & 37.6 & 62.4 \\
\hline
\end{tabular}

Table 3. Responses to multiple choice questions of the survey.

\section{Question}

Percent correct scores (\%)

Q 22: The recommended route of administration of opioid analgesics with brief, severe pain of sudden onset.

e.g. trauma or postoperative pain, is

A: Intravenous

Q 23: The most likely reason a patient with pain would request increased dose of pain medication is?

A: The patient is experiencing increased pain

Q 24: Which approach described the best approach for cultural considerations in caring for patient in pain?

A: Patients should be individually assessed to determine cultural influences

Q 25: Analgesics for post-operative pain should initially be given

A: Around the clock on a fixed schedule

Q 26: The most accurate judge of the intensity of the patient's pain is?

A: The patient

Q 27: What do you think is the percentage of patient who over report the amount of pain they have? Circle the correct answer

A: 0

Q 28: How likely is it that opioid addiction will occur as a result if treating pain with opioid analgesics?

A: $<1 \%-5 \%$ 
analgesics for brief, sever pain of sudden onset (50.6\%); only (18.9\%) of the nurses surveyed correctly indicated that they believed that analgesics for post-operative pain should initially be given around the clock on a fixed schedule. Furthermore, only 125 nurses considered the patient as the most accurate judge of the pain intensity $(28.5 \%)$. Regarding case studies questions answers, nurses were relatively scored correctly in assessment part than management part.

The knowledge questions were grouped into five discrete categories in order to investigate whether the deficits displayed were indication of different aspects of pain management. The specific areas of knowledge included pharmacology, non-pharmacology, assessment, addiction, and patient variables. Results showed that nurses displayed the lowest level of knowledge for assessment (33.2\%), and highest level of knowledge for patient variables (59.1\%).

A one-way ANOVA was performed to examine whether nurses' knowledge scores were statistically significant when compared based on clinical areas where they practiced. Analysis of variance showed that the type of clinical area on pain knowledge scores obtained was significant, $F(6,434)=8.36, P<0.001$. Post-hoc analysis revealed that nurses working in a surgical unit knew significantly more about pain assessment and management issues $(P=0.008)$. Also, the analysis revealed that knowledge did not vary according to employment duration in the clinical unit, $F(4,431)=1.371, P=0.21$.

The analysis investigating whether nurses' age influenced level of knowledge across the five areas of pain management showed that age did not have an effect on specific area of knowledge, $F(4,429)=1.662, P>0.05$. Kruskall Wallis analysis was completed to investigate the effect of employment setting (type of hospital) on the specific area of pain management. A significant main effect was found for employment setting. Post-hoc comparisons showed that nurses employed at private hospitals knew significantly more than nurses employed at public and University-affiliated hospitals $(P<0.001)$.

Nurses with a master degree scored higher than those with baccalaureate degree or associated degree $(P=$ 0.001). Also, Mann-Whitney $U$ test conducted to examine the effect of attending educational course or program on nurses' knowledge of pain assessment or management, nurses who attended educational course or program significantly scored higher than those who had not attend $(P<0.001)$.

Surveyed nurses report possible barriers to effective pain management. Results showed the following percentages as it has never been a barrier that patient were reluctant to report pain, patient were reluctant to take opiods, and nurses were reluctant to give opioids (36.9\%, 28\%, and $27.1 \%$ respectively). While it is always been a barrier the items: patient history of alcohol abuse or drug addiction, and nursing staff reluctant to contact physican for analgesic order (64\% and 31\%, respectively), Table 4 .

\section{Discussion}

This study used a descriptive cross-sectional design to examine Jordanian nurses' knowledge of pain management.

Table 4. Possible barriers to effective pain management.

\begin{tabular}{|c|c|c|c|c|c|}
\hline Barrier & $\begin{array}{c}\text { Never a } \\
\text { barrier } 0 \%\end{array}$ & $\begin{array}{c}\text { Barrier } \\
25 \%\end{array}$ & $\begin{array}{c}\text { Barrier } \\
50 \%\end{array}$ & $\begin{array}{c}\text { Barrier } \\
75 \%\end{array}$ & $\begin{array}{c}\text { Always a barrier } \\
100 \%\end{array}$ \\
\hline Patients' reluctance to report pain & 36.9 & 45.3 & 5.5 & 10 & 2.3 \\
\hline Patients' reluctance to take opioids & 28 & 42.1 & 19.8 & 10.1 & 0 \\
\hline Nursing staff reluctance to give opioids & 27.1 & 29.6 & 20.3 & 23 & 0 \\
\hline Inadequate assessment of pain and pain relief & 16.6 & 41.7 & 36 & 0.5 & 5.2 \\
\hline Lake of time to assess and control pain & 8.2 & 6.4 & 8.9 & 54.7 & 21.8 \\
\hline Physician reluctance/refusal to give analgesic order & 18.2 & 21.2 & 35.3 & 14.8 & 10.5 \\
\hline $\begin{array}{l}\text { Nursing staff reluctance to contact } \\
\text { physician for analgesic orders }\end{array}$ & 0 & 0 & 18 & 51 & 31 \\
\hline Patient history of alcohol abuse or drug addiction & 0 & 0.9 & 5.9 & 29.2 & 64 \\
\hline $\begin{array}{l}\text { The responsibility of caring for other acutely ill } \\
\text { patients in addition to patients experiencing pain }\end{array}$ & 19.1 & 26.7 & 35.3 & 10.7 & 8.2 \\
\hline
\end{tabular}


Principle of justice mandates that all patients should be free from pain. Current findings from this national study maintain the concern of inadequate knowledge and attitudes regarding pain assessment and management. Despite remarkable growth in knowledge and strategies in pain assessment and management, improvement in nursing knowledge and care has not occurred. This deficit can be considered as a barrier to appropriate management.

Jordanian nurses in this study demonstrated deficits in their level of knowledge regarding pain management. The mean correct answer is $13.39(41.84 \%)$ of questions. In general, the surveyed nurses displayed the least amount of knowledge about the assessment of pain, but showed a more comprehensive understanding of the need to vary pain management practices to suit the needs of individual patient (i.e. increased knowledge in area of patient variables). Furthermore, result revealed that nurses have deficits in their knowledge of pain management principles, these deficits appear to be larger than those found in previous studies [24] [28] [35] and less than those found in other studies [27] [36]. Inadequate knowledge of pain assessment and management may be attributed to insufficient educational preparations presented to nurses during their school education. However, nursing educators have to be experts in teaching and training students in these subjects [36]. Educational curriculum should be revised to establish standards and competency in pain assessment and management subjects. Duration and content of these subjects should be adequate [35] and incorporate pharmacological, non-pharmacological methods of reliving pain [25].

Items were nurses scored higher were concerned with patients' variables, and side effect of opioids, similar results reported by Italian and Turkish nurses [28] and [37], respectively. Also, the effect of culture and religious beliefs on patient perception of pain was among the highest score; this can be attributed to the social system Jordanian nurses work within as $97 \%$ of population are Muslims as they believe that suffering is a test from God and a person should tolerate his/her pain and hide it from others.

Nurses report a relatively higher score in the item "patient's self report of pain is the most reliable indicator of pain", and this results were consistent with previous studies [18] [24] [27]. In this study, 28.5\% of the sample answered correctly that patients statement and perception as the most accurate judge of pain intensity. This finding was assured by an earlier work [38]. Regarding areas of pain management knowledge, nurses scored lowest in "assessment" area in this study, this can be related to inadequate preparations in school, lack of pain assessment tools, and lack of continuing education courses on pain assessment and management. Reference [27] found this weakness with Turkish nurses. Reference [39] found that nurses, whom trained to use pain assessment tools, use it in $93 \%$ of the time.

Employment setting was found to influence pain management knowledge. Nurses from private sector hospitals displayed a significant more knowledge regarding areas of pain assessment and management. This can be attributed as private hospital policies and regulations are well-developed in term of patient care and quality of care. Also, it is worthy to mention that in private hospitals patient-nurse ratio is within acceptable level which allow more time for nurses to care for their patients, more continuing education courses are offered to improve nursing care quality, and that patient's satisfaction is a priority; while public and University-affiliated hospitals have less concern regarding these issues. Nurses who worked in surgical units scored relatively higher than nurses worked in other units. This can be explained as those nurse have enough experience to care for patients on pain either before or after surgeries while nurses in other units focus on disease processes and patients hemodynamic [18] [27] [40].

It was obvious that baccalaureate degree holder registered nurses scored higher than diploma or associated degree nurses, as they are more educated and as they are more responsible in assessing pain and providing appropriate management, positive correlation reported in different studies [24] [27] [41]. However, other studies found no significant difference based on education [18] [28]. A total number of 154 participants (35.1\%) were attended an educational programs or courses without any specification regarding the time and period of that program or course. However, they scored significantly higher than those who had not attend, similar results reported in previous studies [28] [42] [43]. Providing staff with adequate and continuing educational materials and information will improve their knowledge level and probably will have effect on their attitude and behavior [44]-[46] [27].

Possible barriers were identified in this study. The most frequently "never been a barrier" was the item Patient were reluctant to report pain, several literature reported that patients were reluctant to interrupt busy nurses, and they were hesitant to request analgesia [16] [44]. Other barriers reported less frequently were that patients were 
reluctant to take opioids, and nurses were reluctant to give opioids, positive correlation was reported by different studies [16] [20]. References [26] [46] [47] ascertain that nurses don't always administer all available analgesia due to knowledge deficit or attitudes or fear of addiction [48]. The study found that "it is always been a barrier" two items: patient history of alcohol abuse or drug addiction, similar findings reported in other studies [49]. The second barrier was nursing staff reluctant to contact physician for analgesic order, Reference [44] described this as chasing-down physicians as it was difficult to contact them [20]. The late barrier affirms the need to institute teamwork between professional as each member take responsibility to provide quality care and lessen patients suffering.

\section{Limitation}

One limitation was identified in the study, the NKAS questionnaire need to be updated to include evolving issues of pain assessment and management field.

\section{Recommendation for Nursing Education}

An early message indicated that pain is a neglected topic in nursing education program [17]. Based on the findings of this study, the following recommendations regarding education are made. First, because educational efforts directed at nurses seem to have contributed to improving their knowledge about pain management, there is justification for the continuation of these efforts. As a whole, it appears that the longer nurses are exposed to correct information about pain management, the better their knowledge levels becomes. Educators and nursing faculty need to be well-equipped with pain assessment and management related knowledge, and to motivate students to learn more about pain.

Second, to maximize the impact of educational courses about pain management, the content of both basic and educational nursing programs (nursing curriculum at universities), needs to be examined critically for relevance and accuracy. Third, clinical practice guidelines regarding various pain management areas in each hospital unit appear to be helpful and should be relied upon in both basic and continuing educational courses to provide current and accurate information.

\section{Implication for Nursing and Health Policy}

Pain management is critical issue for patients; they still suffer from inadequate pain management. There is a need for organizational and political commitment to improve patient care. Availability of enough nursing staff is crucial for any new plans or change as nurses are the cornerstone for any care plan. It is important for nurses to have knowledge and expertise to provide standardized painless care and this can be acquired through regular continuing education in pain assessment and management. Healthcare administrators have to provide continuous support for such efforts though arranging voluntary and mandatory in-service educational programs. On the other hand, hospitals should adopt and implement pain assessment and management protocols and tools based on recent clinical guidelines and evidence-based practice. Administrators have to encourage creating pain management teams and emphasize the importance of collaborative and supportive relationships between team members. Finally, research should be employed to examine the effectiveness of such educational programs and protocols and to create creative guidelines of pain assessment and management.

\section{Conclusion}

This study provided important information about Jordanian nurses' attitude toward pain assessment and management. The results demonstrated knowledge deficit and attitude; nurses underestimated and undertreated patients' pain. Serious efforts should be spent in nursing colleges and hospitals to prepare nurses and equip them with comprehensive tools to assess and manage pain appropriately.

\section{Acknowledgements}

This study funded by the University of Jordan, Amman, Jordan. The authors are grateful for the Deanship of Academic Research, University of Jordan for funding this study and extend their gratitude to Jordanian nurses who participated in this study. 


\section{Conflicts of Interest}

The authors have disclosed no potential conflicts of interest, financial or otherwise.

\section{References}

[1] Chung, J. and Lui, J. (2003) Postoperative Pain Management: Study of Patients' Level of Pain and Satisfaction with Health Care Providers' Responsiveness to Their Reports of Pain. Nursing and Health Sciences, 5, 13-21. http://dx.doi.org/10.1046/j.1442-2018.2003.00130.x

[2] Darawad, M., Al-Hussami, M., Saleh, A., Al-Sutari, M. and Mustafa, W. (2015) Predictors of ICU Patients' Pain Management Satisfaction: A Descriptive Cross-Sectional Survey. Australian Critical Care, 28, 129-133. http://dx.doi.org/10.1016/j.aucc.2014.07.003

[3] Panteli, V. and Patistea, E. (2007) Assessing Patients' Satisfaction and Intensity of Pain as Outcomes in the Management of Cancer-Related Pain. European Journal of Oncology Nursing, 11, 424-533. http://dx.doi.org/10.1016/j.ejon.2007.09.002

[4] Coker, E., Papanaioannou, A., Kaasalainen, S., Dolovich, L., Turpie, I. and Taniguchi, A. (2010) Nurses' Perceived Barriers to Optimal Pain Management in Older Adults on Acute Medical Units. Applied Nursing Research, 23, 139146. http://dx.doi.org/10.1016/j.apnr.2008.07.003

[5] Gauthier, L., Rodin, G., Zimmermann, C., Warr, D., Moore, M., Shepherd, F., et al. (2009) Acceptance of Pain: A Study in Patients with Advanced Cancer. Pain, 143, 147-154. http://dx.doi.org/10.1016/j.pain.2009.02.009

[6] Li, D., Miaskowski, C., Burkhardt, D. and Puntillo, K. (2009) Evaluations of Physiologic Reactivity and Reflexive Behaviors during Noxious Procedures in Sedated Critically Ill Patients. Journal of Critical Care, 24, E9-E13. http://dx.doi.org/10.1016/j.jcrc.2008.07.005

[7] Marmo, L. and Fowler, S. (2010) Pain Assessment Tool in the Critically Ill Post-Open Heart Surgery Patient Population. Pain Management Nursing, 11, 134-140. http://dx.doi.org/10.1016/j.pmn.2009.05.007

[8] The Institute of Medicine (IOM) (2011) Relieving Pain in America: A Blueprint for Transforming Prevention, Care, Education, and Research. National Academic Press, Washington DC.

[9] Joint Commission on Accreditation of Healthcare Organizations (JCAHO) (2000) Joint Commission on Accreditation of Healthcare Organizations. Pain Assessment and Management: An Organizational Approach. Joint Commission Resources, Washington DC.

[10] Blondal, K. and Halldorsdottir, S. (2009) The Challenge of Caring for Patients in Pain: From the Nurse's Perspective. Journal of Clinical Nursing, 18, 2897-2906. http://dx.doi.org/10.1111/j.1365-2702.2009.02794.x

[11] Dreidi, H. and Hamdan-Mansour, A. (2015) Pain, Sleep Disturbance, and Quality of Life among Palestinian Patients Diagnosed with Cancer. Journal of Cancer Education, 30, 736-742. http://dx.doi.org/10.1007/s13187-015-0946-5

[12] Niemi-Murola, L., Pöyhiä, R., Onkinen, K., Rhen, B., Mäkelä, A. and Niemi,T. (2007) Patient Satisfaction with Postoperative Pain Management-Effect of Preoperative Factors. Pain Management Nursing, 8, 122-129. http://dx.doi.org/10.1016/j.pmn.2007.05.003

[13] European Association of Palliative Care (2007) Half of European Cancer Patients Have Moderate to Severe Pain: One in Five Patients Does Not Receive Treatment. Journal of Pain \& Palliative Care, 21, 51-53.

[14] Hamill-Ruth, R. and Marohn, M. (1999) Evaluation of Pain in the Critically Ill Patient. Critical Care Clinic, 15, 35-54. http://dx.doi.org/10.1016/S0749-0704(05)70038-5

[15] Pasero, C. (2003) Pain in the Emergency Department: Withholding Pain Medication Is Not Justified. American Journal of Nursing, 103, 73-74. http://dx.doi.org/10.1097/00000446-200307000-00025

[16] Coulling, S. (2005) Nurses' and Doctors' Knowledge of Pain after Surgery. Nursing Standard, 19, 41-49. http://dx.doi.org/10.7748/ns2005.05.19.34.41.c3859

[17] McCaffery, M. and Robinson, E. (2002) Your Patient Is in Pain: Here's How You Respond. Nursing, 32, 36-47. http://dx.doi.org/10.1097/00152193-200210000-00042

[18] Lui, L., So, W. and Fong, D. (2008) Knowledge and Attitudes Regarding Pain Management among Nurses in Hong Kong Medical Units. Journal of Clinical Nursing, 17, 2014-2021. http://dx.doi.org/10.1111/j.1365-2702.2007.02183.x

[19] Vincent, C. (2005) Nurses' Knowledge, Attitudes, and Practices: Regarding Children's Pain. MCN American Journal of Maternal \& Child Nursing, 30, 177-183.

[20] Elcigil, A., Maltepe, H., Esrefgil, G. and Mutafoglu, K. (2011) Nurses' Perceived Barriers to Assessment and Management of Pain in a University Hospital. Pediatric Hematology Oncology, 33, S33-S38. http://dx.doi.org/10.1097/MPH.0b013e3182121bef

[21] McCaffery, M. and Pasero, C. (1999) Pain Clinical Manual. Mosby, St. Louis. 
[22] He, H., Jahja, R., Lee, T., Ang, E., Sinnappan, R., Vehviläinen-Julkunen, K. and Chan, M. (2010) Nurses' Use of Non-Pharmacological Methods in Children's Postoperative Pain Management: Educational Intervention Study. Journal of Advanced Nursing, 66, 2398-2409. http://dx.doi.org/10.1111/j.1365-2648.2010.05402.x

[23] Rejeh, N., Ahmadi, F., Mohammadi, E., Kazemnejad, A. and Anoosheh, M. (2009) Nurses' Experiences and Perceptions of Influencing Barriers to Postoperative Pain Management. Scandinavian Journal of Caring Sciences, 23, 274-281. http://dx.doi.org/10.1111/j.1471-6712.2008.00619.x

[24] Wang, H. and Tsai, Y. (2010) Nurses' Knowledge and Barriers Regarding Pain Management in Intensive Care Units. Journal of Clinical Nursing, 19, 3188-3196. http://dx.doi.org/10.1111/j.1365-2702.2010.03226.x

[25] Matthews, E. and Malcolm, C. (2007) Nurses' Knowledge and Attitudes in Pain Management Practice. British Journal of Nursing, 16, 174-179. http://dx.doi.org/10.12968/bjon.2007.16.3.22972

[26] Moceri, J. and Drevdahl, D. (2014) Nurses' Knowledge and Attitudes toward Pain in the Emergency Department. Journal of Emergency Nursing, 40, 6-12. http://dx.doi.org/10.1016/j.jen.2012.04.014

[27] Yava, A., Cizek, H., Ozcan, C., Yildiz, D. and Dizer, B. (2013) Knowledge and Attitudes of Nurses about Pain Management in Turkey. International Journal of Caring Sciences, 6, 494-505. http:/www.internationaljournalofcaringsciences.org/docs/23.\%20Yava.pdf

[28] Bernardi, M., Catania, G., Lambert, A., Tridello, G. and Luzzani, M. (2007) Knowledge and Attitudes about Cancer Pain Management: A National Survey of Italian Oncology Nurses. European Journal of Oncology Nursing, 11, 272-279. http://dx.doi.org/10.1016/j.ejon.2006.09.003

[29] AlQadire, M. and Alkhalaileh, M. (2012) Jordanian Nurses Knowledge and Attitude Regarding Pain Management. Pain Management Nursing, 15, 220-228. http://dx.doi.org/10.1016/j.pmn.2012.08.006

[30] Darawad, M., Al-hussami, M., Saleh, A. and Al-Sutari, M. (2012) Jordanian Patients' Pain Management Satisfaction. Pain Management Nursing, 15, 116-125. http://dx.doi.org/10.1016/j.pmn.2012.07.005

[31] Hweidi, I. (2007) Jordanian Patients' Perception of Stressors in Critical Care Units: A Questionnaire Survey. International Journal of Nursing Studies, 44, 227-235. http://dx.doi.org/10.1016/j.ijnurstu.2005.11.025

[32] Abdalrahim, M., Majali, S. and Bergbom, I. (2008) Documentation of Postoperative Pain by Nurses in Surgical Wards. Acute Pain, 10, 73-81. http://dx.doi.org/10.1016/j.acpain.2008.04.001

[33] Al-Shaer, D., Hill, P. and Anderson, M. (2011) Nurses Knowledge and Attitudes Regarding Pain Assessment and Intervention. Medsurg Nursing, 20, 7-11. http://www.ncbi.nlm.nih.gov/pubmed/21446289

[34] Ferrell, B. and McCaffery, M. (2008) The Nurses' Knowledge and Attitudes Survey Regarding Pain. http://prc.coh.org/Knowldege $\% 20 \% 20 \& \% 20$ Attitude $\% 20$ Survey $\% 207-14$.pdf

[35] Lai, H., Chen, M., Tsai, L., Lo, L., Wei, L., Hong, M., et al. (2003) Are Nurses Prepared To Manage Cancer Pain? A National Survey of Nurses' Knowledge about Pain Control in Taiwan. Journal of Pain and Symptom Management, 26, 1016-1025. http://dx.doi.org/10.1016/S0885-3924(03)00330-0

[36] Démeh, W. and Rosengren, K. (2015) The Visualisation of Clinical Leadership in the Content of Nursing Education-A Qualitative Study of Nursing Students' Experiences. Nurse Education Today, 35, 888-893. http://dx.doi.org/10.1016/j.nedt.2015.02.020

[37] Yildirim, Y., Fadiloglu, C. and Uyar, M. (2008) Knowledge and Attitudes of Turkish Oncology Nurses about Cancer Pain Management. Pain Management Nursing, 9, 17-25. http://dx.doi.org/10.1016/j.pmn.2007.09.002

[38] McCaffery, M. and Beebe, A. (1989) Pain: Clinical Manual for Nursing Practice. Mosby, St. Louis.

[39] Bouvette, M., Fothergill-Bourbonnais, F. and Perreault, A. (2002) Implementation of the Pain and Symptom Assessment Record (PSAR). Journal of Advanced Nursing, 40, 685-700. http://dx.doi.org/10.1046/j.1365-2648.2002.02428.x

[40] Sutari, M., Abdul-Rahim, M., Hamdan-Mansour, A. and Ayasreh, S. (2014) Pain among Mechanically Ventilated Patients in Critical Care Units. Journal of Research in Medical Sciences, 19, 726-732.

[41] Lewthwaite, B., Jabusch, K., Wheeler, B., Schnell-Hoehn, K., Mills, J. and Estrella-Holder, E. (2011) Nurses’ Knowledge and Attitudes Regarding Pain Management in Hospitalized Adults. Journal of Continuing Education in Nursing, 42, 251-257. http://dx.doi.org/10.3928/00220124-20110103-03

[42] Patiraki, E., Papathanassaoglou, E., Tafas, C., Akarepi, V., Katsaragakis, S., Kampitsi, A. and Lemonidou, C. (2006) A Randomized Controlled Trial of an Educational Intervention on Hellenic Nursing Staff's Knowledge and Attitudes on Cancer Pain Management. European Journal of Oncology Nursing, 10, 337-352. http://dx.doi.org/10.1016/j.ejon.2005.07.006

[43] Tsai, F., Tsai, Y., Chien, C. and Lin, C. (2007) Emergency Nurses' Knowledge of Perceived Barriers in Pain Management in Taiwan. Journal of Clinical Nursing, 16, 2088-2095. http://dx.doi.org/10.1111/j.1365-2702.2006.01646.x

[44] Yacoub, M., Demeh, W., Darawad, M., Barr, J., Saleh, A. and Saleh M. (2014) An Assessment of Diabetes-Related Knowledge among Registered Nurses Working in Hospitals in Jordan. International Nursing Review, 61, 255-262. 
http://dx.doi.org/10.1111/inr.12090

[45] Aiken, L., Cimiotti, J., Sloane, D., Smith, H., Flynn, L. and Neff, D. (2011) Effects of Nurse Staffing and Nurse Education on Patient Deaths in Hospitals with Different Nurse Work Environments. Medical Care, 49, 1047-1053. http://dx.doi.org/10.1097/MLR.0b013e3182330b6e

[46] Twycross, A. (2013) Nurses' Views about the Barriers and Facilitators to Effective Management of Pediatric Pain. Pain Management Nursing, 14, 164-172. http://dx.doi.org/10.1016/j.pmn.2011.10.007

[47] Manias, E. (2003) Medication Trends and Documentation of Pain Management Following Surgery. Nursing \& Health Sciences, 5, 85-94. http://dx.doi.org/10.1046/j.1442-2018.2003.00140.x

[48] Ratrout, H., Hamdan-Mansour, A., Samer, S., Seder, S. and Salim, W. (2013) Patient Satisfaction about Using Patient Controlled Analgesia in Managing Pain Post Surgical Intervention. Clinical Nursing Research, 23, 353-368. http://dx.doi.org/10.1177/1054773813488418

[49] Duignan, M. and Dunn, V. (2009) Perceived Barriers to Pain Management. Emergency Nurse, 16, 31-35. http://dx.doi.org/10.7748/en2009.02.16.9.31.c6848 